\title{
Estudo da sala de aula com aporte teórico-metodológico da hermenêutica objetiva ${ }^{1}$
}

Rita Amélia Teixeira Vilela*

\begin{abstract}
Resumo
\end{abstract}
*Docenteaposentadapela UFMG e Docente do PPGE da PUC Minas.
${ }^{1}$ Texto apresentado em João Pessoa no Colóquio Internacional de Políticas e Práticas Curriculares, em novembro de 2011.

$\mathrm{E}$ ste texto apresenta a discussão de pesquisa realizada com aplicação da metodologia hermenêutica objetiva (OEVERMANN, 2009), em duas escolas particulares e duas públicas. Foram acompanhadas e gravadas aulas de português e matemática nas escolas particulares, e aulas de história, português e ciências nas escolas públicas. Em cada escola foram registradas, em áudio, aulas em uma turma de cada disciplina, em uma variação de 8 a 12 horas em cada classe, acompanhando uma sequência de aulas relativas a uma unidade de conteúdo. Segundo o método, essas aulas gravadas são transcritas e constituem o protocolo, que é o documento que representa a aula e é analisado. Considerado pronto para análise, nenhuma informação pode ser acrescentada ao protocolo. Devido a isso, o texto é revisado e dúvidas devem ser esclarecidas com os pesquisadores que estiveram presentes na sala de aula e suas anotações no caderno de campo e, se necessário, nova consulta aos registros em áudio. Todas as situações que indicam particularidades da aula (tais como entonação de voz, risos, barulhos, etc.) são também registradas através de codificação. Devido a isso, há a necessidade de conhecimento do método pelos analistas das aulas e eles foram formados para esse trabalho, tanto para a operacionalização do processo quanto na compreensão de sua epistemologia, fundada na dialética negativa de Theodor Adorno, na hermenêutica sociológica e na sociologia estruturalista (VILELA; 
NOACK-NÁPOLIS, 2010; VILELA, 2010).

A análise dos dados em equipe, no caso das aulas, com a presença inconteste de um professor da disciplina da aula em análise, visa garantir a operacionalidade anunciada nas regras do método2: evitar que a subjetividade de uma única pessoa se projete na interpretação; possibilitar que diferentes pontos de vistas possam ser expressados e testados com os fatos registrados; possibilitar o cruzamento de interpretações dadas por diferentes pessoas diante de uma mesma situação registrada; testar e assegurar a objetividade da interpretação. Após a análise de cada passagem do protocolo, a equipe elabora uma síntese de cada aula, destacando as situações constantes e que permitem afirmar sua característica dominante (ou várias preponderantes). Ao final, essa síntese de cada aula é contrastada com as sínteses das demais para se obter uma conclusão. É necessário que os envolvidos na pesquisa tenham em mente uma pergunta norteadora do processo: o que revela a sala de aula sobre a escola? Ou, qual escola a sala de aula nos revela? A análise deve assegurar que se chegue a esse conhecimento.

Após a análise sequencial, temos uma descrição analítica de como essa aula serealizou. Diferente das pesquisas usuais da sala de aula, no lugar de observar uma aula e depois escrever uma interpretação sobre ela, a hermenêutica objetiva reconstitui analiticamente a aula.

\section{Os resultados da pesquisa}

No final do processo de análise, isto é, após a síntese de cada aula e a contrastação entre elas, preparamos uma síntese conclusiva. As aulas não foram comparadas, apenas buscamos nelas elementos que foram permanentes e que permitem algumas conclusões.

Não partimos de um plano curricular, mas, da proposição curricular abrangente que estabelece como função da escola preparar pessoas cidadãs, preparadas para a vida social, função que é histórica à escola desde sua edificação (MONROE, 1976) e que está estabelecida, formalmente, para as escolas brasileiras, nos Parâmetros Curriculares Nacionais (BRASIL, 1997). Em primeiro lugar, a função da escola é conduzir os alunos a desenvolverem suas habilidades básicas de aprendizagem e conduzir todos os alunos à plena condição de exercício da cidadania, ou seja, que cada um se complete como indivíduo desenvolvendo suas competências culturais e sociais. Isso inclui acesso e domínio de conhecimento, capacidade de reflexão e de agir com autonomia. O debate no campo do currículo reconhece que, no processo de escolarização, os alunos têm esse direito e isso lhes deve ser assegurado através das atividades e experiências organizadas no currículo: o acesso aos conhecimentos culturais e técnicos condizentes com a faixa etária e o nível de ensino, e que esses conhecimentos correspondam em qualidade às necessidades da vida social (MOREIRA; GARCIA, 2003; MCKERNA, 2009; GOODSON, 2006). O reconhecimento dessa função está assumida nas determinações legais para a escola brasileira que demanda que a ação da escola deve visar o desenvolvimento da autonomia dos alunos, "desenvolvendo o sentimento de segurança em relação às 
suas próprias capacidades, interagindo de modo orgânico e integrado num trabalho de equipe e, portanto, sendo capaz de atuar em níveis de interlocução mais complexos e diferenciados" (BRASIL, 1997, p.35).

Portanto, duas dimensões deveriam emergir das análises das salas de aula em relação à proposição curricular explícita: a lida com o conhecimento e o processo de formação dos alunos para autonomia. Como nosso amparo teórico para a discussão da sala de aula é a Teoria Crítica de Theodor Adorno, nossa discussão desse processo foi conduzida no diálogo das evidências da pesquisa com as posições de Adorno acerca da escola: sua crítica aos processos pedagógicos e sua reivindicação para a escola.

\section{Exemplo da aula analisada até a síntese da aula.}

Não será registrada aqui a íntegra de uma aula analisada. Esse é um documento que constitui nosso banco de dados e será disponibilizado para domínio público em breve no site do Programa de Pós-Graduação em Educação - PPGE - da PUC Minas, bem como o Relatório Técnico da pesquisa. Além disso, cada aula analisada produz um texto de cerca de 70 a 90 páginas, impossível de constar em um artigo. Para a discussão a ser apresentada neste texto segue, como modelo exemplificador do processo, apenas um pequeno trecho de uma aula analisada.

Aula: Ciências

Horário: 7h às 7h50

Turma: 900 - $9^{\circ}$ ano, (39 alunos)

Obs.: Os alunos estão codificados. A indicação numérica é possível porque os pesquisadores fizeram no caderno de campo o mapa da classe e numeram os alunos. Como eles acompanham a aula, marcam no mapa a sequência da fala dos alunos, identificada no numero o aluno em questão. O tempo da aula é marcado a cada 10'.

7h10min

A professora chega à sala para o início da aula.

- Observamos aqui, o desrespeito ao tempo-aula: o horário de início da aula é 7h, a professora chega à sala às $7 \mathrm{~h} 10$. Seria esse um procedimento habitual

- ou estamos sendo confrontados com uma situação de exceção? De qualquer modo, isso é um tempo negado ao processo de educar, ensinar e aprender.

Professora: "Ó gente!"

- A professora utiliza uma maneira peculiar de se referir aos alunos, indicando, em primeiro lugar, que se refere aos alunos como a qualquer grupo. Por exemplo, por que ela não se dirige a eles como "meus alunos" ou "classe tal", que indicaria o estabelecimento do tipo de relação existente no espaço de uma sala de aula? 
Em que situações de relação social encontra-se, com regularidade, essa forma de estabelecimento de relação? Essa é uma forma de abordagem em relações impessoais em grandes grupos, por exemplo, de um animador de auditório ou um policial dirigindo-se a um grande grupo de pessoas: "gente, respeitar a linha demarcatória para não avançar!" Usada na sala de aula assume um sentido diferente, ou o professor está estabelecendo uma relação impessoal?

- Em segundo lugar indica, também, uma impropriedade na relação entre o professor e seus alunos, considerando que na relação pedagógica o professor tem uma posição de autoridade, deve agir como professor e tratar os alunos como alunos. Ao usar a expressão "gente", ela revela um papel semelhante a qualquer outro sujeito que está se dirigindo a pessoas em geral, não especificamente a alunos.

- É o momento de início de um dia, de uma aula e de uma situação comunicativa, em que a professora encontra-se com o grupo pela primeira vez, naquela data. A forma de abordar os alunos substituiu um cumprimento que seria esperado nessa situação, pois, o cumprimento é substituído por um vocativo: "Gente!".

- A falta de cordialidade se destaca não só pela ausência de um cumprimento como, por exemplo, "um bom dia", mas também pela falta de um pedido de desculpas pelo atraso. Seria essa atitude de falta de cortesia habitual? Em um ambiente, no qual se espera que sejam desenvolvidas formas de relação consideradas adequadas para a convivência em sociedade, essas formas de relação não deveriam ser vivenciadas dentro da sala de aula?

\section{Professora: "Atenção aqui."}

- Segue-se um comando explícito, que, aparentemente, procura dar relevância ao papel educativo da professora, pois Ihe cabe a iniciativa de estabelecer na classe um comando que assinale o momento de iniciar a atividade do dia.

- O uso da expressão "atenção aqui", reforça a busca, por parte da professora, de ocupar um lugar central na sala de aula. "Atenção aqui" remete à ideia de que a professora aponta que ela deve ser notada como a condutora do trabalho - eu vou dizer o que fazer, prestem atenção! Isso dá o tom que permeará o seu transcurso. Ela comanda, os alunos concordam, aceitam e fazem o que for estabelecido.

- A utilização do "aqui" reforça essa ideia, uma vez que não está indicando um lugar e sim a sua pessoa. Essa tentativa de ser a protagonista da ação, aliás, um papel adequado à situação de professor, também indica sua vontade de dar início à atividade e que há algo estabelecido que deve acontecer. Mas, esse protagonismo se daria apenas em um momento em que haverá uma comunicação a ser feita, ou será mantido em outros momentos da aula? 
- A construção "Ó gente! Atenção aqui" mescla o informal, expresso pelo " ó gente", com a busca do formal "atenção aqui".

- O sentido da expressão "atenção aqui" é retórico, uma vez que se pede a atenção, mas não se sabe ainda o que será anunciado, havendo, apenas, o anúncio de um evento. Não há, ainda, uma explicação, na frase, do que consistirá a aula que justifique o pedido de atenção.

Professora: "Eu tenho que dar o visto até o final dos 50 minutos."

- O uso da expressão "eu tenho que" indica certa obrigatoriedade em ter que "dar visto" em algo. Reforça a ideia de que o cumprimento da tarefa, ainda não anunciada, é a finalidade última a ser estabelecida. Não importa se os processos de aprendizagem serão percorridos. Afinal, "dar o visto" não é garantia de que haverá envolvimento efetivo com uma atividade. Se for um exercício, ele não será corrigido, apenas controlado se foi executado. Se executado, recebe o visto.

- Entretanto, pela primeira vez, aparece o indício de que algo seria realizado com os alunos, talvez um exercício, passível de receber um visto. Mas surge um outro elemento: haverá controle, pois, ela daria um visto, o reconhecimento de que a tarefa teria sido cumprida.

- Na expressão "até o final dos 50 minutos" o limite temporal criado pelo uso do vocábulo "até" reforça a tendência presente na fala inicial de que é o final do tempo que determinará o cumprimento de uma tarefa. Mesmo estando ela inacabada, isso não importa como indicador se o aluno deu conta porque não sabe ou porque o tempo é curto, terminado o tempo a tarefa tem seu ponto final. Portanto, o cumprimento da tarefa está condicionado à sua duração, o cumprimento de um tempo estabelecido para envolvimento com um fazer

- pelo fazer e não ao sentido do que deveria ser feito. Não há preocupação se haverá aprendizado, somente com o tempo do término da tarefa. Esse "tarefa terminada" não significa, assim, que foi feita correta e, muito menos que os alunos demonstraram ter aprendido o conteúdo em pauta.

- O prazo estabelecido é de 50 minutos, porém a professora não admite que, com seu atraso, não há mais 50 minutos disponíveis, e sim 40 . Seria uma negação de seu atraso? Seria uma forma de camuflar a perda de 10 minutos de aula, devido à falta de pontualidade no início da aula? Trata-se de uma situação tão naturalizada que não importa o atraso, a aula é aula de 50 minutos, sejam eles reais ou não? Mas, o tempo de que os alunos dispõem para obedecer aos comandos é incompatível ao tempo designado pela professora.

- No processo pedagógico, cabe ao professor preparar os alunos para a aula. Essa dimensão não esteve presente no começo dessa aula. No início da aula, o papel da professora seria estabelecer que a função educativa fosse contemplada, abrindo para os alunos a possibilidade de instalação do processo de aprendizagem. Isso 
não aconteceu, ela não criou situações desafiadoras para o envolvimento dos alunos com a aprendizagem - não anunciou o que os envolveria como tarefa, não despertou interesse. Isso pode resultar numa situação educativa contrária ao desenvolvimento da autonomia e da criatividade - os alunos aprendem o fazer pelo fazer.

Professora: "Está certo?"

- Nenhum aluno respondeu e nem a professora permitiu que o tempo fosse suficiente para uma resposta.

- É uma pergunta de conotação retórica, que serve para ratificar a posição de autoridade assumida - "vocês vão fazer a tarefa até o final da aula." Não existe outra alternativa.

- Não houve um convite para a aula, mas, já o anúncio de forma impositiva sobre uma atividade que deveria ser realizada e controlada.

Professora: "Vamos começar?"

( ...) fica interrompida a apresentação da aula analisada. Até aqui apenas 2 minutos da aula.

Segue a fala final da professora:

7 h52min

Professora: "Ó gente, trazer prá mim na próxima aula prá mim dar o visto. Quem não conseguir terminar, tá?"

- E assim termina a aula, "tarefa começada e terminada" para quem recebeu o visto, caso contrário, ainda continua. Quem não conseguiu terminar deve trazer pronto na aula seguinte e apresentar a tarefa para receber o visto.

- A atitude da professora, no final da aula, indica que ela tem pressa. É anunciado que o tempo aula está chegando ao fim e, como ela havia dito no início , "tem

- que terminar", a aula era "para começar e terminar em 50 minutos". Ela vê o erro, dá uma solução rápida e imediata para que seja corrigido, sem se preocupar se houve compreensão ou não. Na verdade, essa foi a conduta presente em toda a aula, no lugar de possibilitar ao aluno refletir sua dúvida e buscar ele mesmo a resposta, compreendendo a questão envolvida, ela sempre deu as respostas, de forma apressada e, muitas vezes com erros ${ }^{3}$.

\section{Análise conclusiva dessa aula (todos os elementos constantes na análise estão comprovadas na análise sequencial da aula)}

Todas as situações destacadas na análise demonstram que a professora não conduziu o processo de aprendizagem, mas sim controlou a montagem de um gabarito segundo ordens - deveria ser completado, linhas pontilhadas deveriam ser 
respeitadas, era necessário colorir ao final, numerar previamente as imagens dos pares de cromossomas para que "eles não se perdessem". No $9^{\circ}$ ano, os alunos encontramse ainda em processo de aprender apenas noções elementares de cumprir as tarefas escolares.

- Persistiu a redução do conhecimento científico a um mero contar de cromossomos de papel e colagem de recortes de papel em folhas de gabarito. A aula parece ser a resolução de um quebra-cabeças, em que a professora joga as peças e cada aluno vai montando de acordo com o seu entendimento.

- A professora demonstrou sempre atitude de controle sobre a execução da tarefa, uma vez que ela traduziu todas as perguntas como sendo dúvidas em relação ao gabarito e não quanto ao conteúdo. Definiu o seu lugar e o dos alunos: ela determina e eles fazem, ela fornece a resposta, a solução, eles devem aceitá-la e escrevê-la no gabarito.

- Foi permanente sua falta de percepção sobre as dúvidas dos alunos: ela não refletia as perguntas do aluno para poder elaborar uma resposta que os ajudassem no processo de entendimento. A professora abordou todas as dúvidas formuladas pelos alunos como dúvidas na execução da tarefa mecânica: como preencher o gabarito, como organizar o material para preencher o gabarito. Nessa situação foi também incapaz de criar situações para que os próprios alunos usassem da reflexão para a busca de respostas ou soluções para os impasses enfrentados por eles na execução da tarefa.

- Ao final da aula, ao se referir aos alunos no momento em que o cumprimento da tarefa deve chegar ao final, e quando parece evidente que os alunos não conseguiram completar o gabarito como deviam, ou há erros ou incompletude, então a culpa é deles, ela não vê sua responsabilidade pelo ocorrido - o fato de que nem todos os alunos conseguiram terminar o gabarito e a possiblidade de que aqueles que o fizeram não o fizeram correto, ou da melhor forma.

- Não foram captados em toda a aula momentos criados para se instalar uma dimensão reflexiva sobre os erros, sobre as dificuldades na realização da tarefa que, possivelmente, faria emergir as dificuldades com o conteúdo em questão e que, então, ainda pudesse resgatar nessa aula seu processo educativo.

- Ao término da aula, evidenciaram-se as consequências da desorganização e desinformação que imperou desde o seu início. Por todos os lados da sala, os alunos chamam pela professora com muitas dúvidas ainda sobre "colar", "recortar" e "colorir", mas quando querem saber se o que fizeram estava "certo", sugeriam que a dúvida na tarefa não estava dissociada da dúvida com o conhecimento, que esse não ocorreu ou que não se completou com a atividade. 
- Ao final do tempo-aula, é chegada a hora de dar o visto, de controlar o cumprimento da tarefa, "começar e terminar", como estabeleceu na sua primeira fala aos alunos; não importa se terminaram e muito menos se fizeram correto; se houve compreensão; se os alunos se apropriaram de conhecimentos sobre síndromes; ou sobre combinações genéticas. Todos receberão o visto, foi essa a meta da aula, "começar e terminar". O término é o visto, e não a completude do exercício e muito menos o que ele significou para os alunos. "Ter" o visto é sinal de tarefa cumprida, não do aprendizado realizado.

- Entretanto, na aula, as dúvidas dos alunos ficaram evidentes, eles demonstraram momentos em que estavam perdidos, aparentemente, com a tarefa, perdidos na colagem, perdidos com os papéis. Mas a tarefa que deveriam fazer era banal: duas folhas com figuras de pares de cromossomos que deveriam ser recortadas e coladas em duas folhas de gabarito, um representando uma disposição genética que indica a síndrome de Turner, e outro a síndrome de Down. Se os alunos tivessem os conhecimentos sobre as síndromes e sobre a disposição genética, teriam feito a tarefa de modo rápido. Habilidade essas de recorte, de colagem e de colorir que deveriam ter sido adquiridas nos primeiros anos da educação infantil. Portanto, estarem perdidos com os papéis significava estarem perdidos com o conhecimento, que eles não dispunham para realizar a tarefa. As dúvidas emitidas por alunos em todo o grupo de trabalho envolvidos com a tarefa denotaram isso, que a dificuldade com a tarefa era a dificuldade com o conhecimento. Mas a professora não percebeu isso, considerou o conteúdo dado porque os alunos foram recomendados a lerem em casa o texto no livro, eles foram avisados que fariam uma tarefa em classe, usando as informações que estavam no livro 4 . O conhecimento, de qualquer forma, não pode ser reduzido a um texto de livro.

- A aula, que transcorreu com total banalização da lida com as informações a respeito das duas síndromes, negou aos alunos uma experiência plena com o conteúdo, eles não tiveram acesso a essa experiência, foram submetidos a uma mera distribuição de cromossomos impressos em papel para recortar e colar. A professora não conduziu o exercício como suporte da aprendizagem.

- Pode-se montar um cariótipo com imagens de pares de cromossomas5, mas não se pode, apenas com essa montagem, sem discussão com base em informações, entender as síndromes genéticas. Em toda a aula não houve menção ao conhecimento sobre elas: porque são causadas, suas características e como afetam as pessoas e as dimensões sociais envolvidas. Houve equívoco na condução da professora, um deles foi ter reforçado a abordagem das síndromes como doenças, fortalecendo o que é presente no senso comum 6 . 
- O outro problema foi a introdução e manutenção da explicação errada sobre a síndrome de Turner, isso porque a professora tentou discuti-la numa situação de comparação com a síndrome de Down. As duas são genéticas, portanto, de fato resultantes de alterações genéticas, como algumas outras, informação a que os alunos não tiveram acesso. Mas, elas são diferentes na constituição e na forma como afetam os portadores, a de Turner está relacionada com cromossomas determinantes de características sexuais, a de Down não, informação que foi negada aos alunos. A professora cometeu erro ao associar a síndrome de Turner com o cromossoma masculino. Afirmando que ela afeta indivíduos masculinos, o erro é grave não só pelo próprio erro, mas também porque há outra síndrome relacionada a alterações genéticas e que afeta o sexo masculino, informação negada e que seria facilitadora da compreensão da síndrome. A professora parece desconhecer isso e induz os alunos a confusões e erros.

- Finalmente, a aula pode ser interpretada como uma aula para o disciplinamento dos alunos em execução de tarefas - receber e cumprir ordens, cumprir o tempo. Ela não promoveu as condições necessárias ou desejáveis para lidarcom informações e conhecimento, e não criou experiências de desenvolvimento de autonomia. Sendo que disciplinar, como função da escola quando se sobrepõe à função esperada, ou seja, desenvolver a autonomia e acesso ao conhecimento para a vida social dos sujeitos é uma redução da competência da escola. Ser disciplinado na escola significa ser disciplinado (adaptado sem questionar) na vida social. Isso é contrário a uma proposição de escola que prepara o cidadão para uma vida ativa na sociedade.

\section{Conclusões possíveis a partir do conjunto das aulas analisadas}

No conjunto das aulas analisadas, após a contrastação das sínteses de cada uma delas, podemos destacar os elementos que nos permitem, primeiro, responder se as proposições curriculares (acesso ao conhecimento e desenvolvimento de autonomia), estabelecidas pelos parâmetros Curriculares (BRASIL, 1997), são materializadas na sala de aula, ou seja, se as aulas favorecem situações que levam os alunos a desenvolverem domínio de conteúdo e o desenvolvimento de autonomia de modo a se tornarem pessoas ativas e em condições de assumir sua própria vida. Em segundo lugar, nos permite discutir o que significa a escola, quais sentidos ela revela, segundo a posição de Theodor Adorno.

\section{Destaques da análise contrastiva das aulas}

Após a análise sequencial, temos uma descrição analítica de como cada aula se realizou. Após o contraste das sínteses elaboradas para cada uma das aulas, foram 
demarcadas algumas características indicadoras de uma situação de escola. Assim, tentamos responder à nossa indagação: que escola está revelada na sala de aula? Nesta, os destaques revelam:

\section{Sobre a socialização ou cultura da escola}

Não se efetiva a educação pela autonomia - prevalecem as dimensões de adestramento e disciplinamento em relação a normas e tarefas:

- alunos são treinados para seguir ordens, valorizar notas ou pontos ganhos como uma contabilidade de que folhas de exercício entregaram;

- não há espaços para pensamentos divergentes, não se instalam desafios para aprendizagem;

- a experiência social dos alunos é pobre num ambiente onde as atividades são delimitadas ao cumprimento de tarefas, entrega de papéis com exercícios, visando nota e não aprendizagem; os respectivos papéis, de alunos e professores não podem ser bem exercidos nocontexto encontrado

\section{Sobre relação ensinar e aprender}

O conhecimento não se efetiva, ele é negado ao aluno:

- o trabalho didático do professor, empreendido como sua competência técnica na área de conteúdo que representa, está comprometido com professores que reforçam categorias do senso comum e permitem a circulação de informações erradas;

- o processo de levar os alunos a aprenderem diferentes formas de aprender não é favorecido em aulas com discurso sobre o tema: não se aprende física com discurso sobre física, o mesmo vale para matemática e ciências; memorização de fatos e informações nas aulas de história e geografia não podem ser tratadas como conhecimento;

- no ambiente onde são fortalecidos o senso comum, informações generalizadas e descontextualizadas, ou até informações erradas, é negada ao aluno a experiência com o conhecimento acadêmico e cultural, que é seu direito.

\section{Sobre a formação pessoal para a autonomia}

Essa dimensão é fraca na sala de aula, ou inexistente:

- está enfraquecida as possibilidades dos alunos na aquisição de conhecimentos e de desenvolvimento de habilidades, de autonomia e criatividade que possam Ihes assegurar acesso ao conhecimento, ao entendimento da sociedade e ao estabelecimento de relações sociais desejáveis ao desenvolvimento de uma sociedade igualitária; 
- sob controle e execução de tarefas para fins estabelecidos (para o professor/ para nota) o alunos não se desenvolvem como pessoas autônomas, a escola reforça a heteronomia e se confirma como o lugar da semiformação (conceitos de Theodor Adorno para denominar o processo de não autonomia).

A síntese esquemática acima permite afirmar que a proposição curricular estabelecida nos Parâmetros Curriculares não se materializa na sala de aula. O que se efetiva é seu contrário: negação de conhecimento e não desenvolvimento de autonomia. Isso fica evidente nas situações arroladas no quadro sintético acima registrado, decorrente das seguintes situações, evidenciadas na reconstituição das aulas.

Assim, o resultado da pesquisa aponta que a escola revelada nas salas de aula não corresponde de forma positiva à sua função de conduzir os alunos a desenvolverem suas habilidades básicas de aprendizagem para que alcancem a plena condição de exercício da cidadania. Eles estão sendo negligenciados em relação ao seu direito ao acesso aos conhecimentos culturais e técnicos condizentes com sua faixa etária e com o nível de ensino. Não estão adquirindo conhecimentos que correspondam em qualidade ao que precisam para suas necessidades da vida social. Além disso, aceitando que a ação da escola deve visar o desenvolvimento da autonomia dos alunos, "desenvolvendo o sentimento de segurança em relação às suas próprias capacidades, interagindo de modo orgânico e integrado num trabalho de equipe e, portanto, sendo capaz de atuar em níveis de interlocução mais complexos e diferenciados" (BRASIL, 1997, p.35), essa experiência não se faz presente na sala de aula. A proposição curricular não se materializa na sala de aula, esta tem se revelado um ambiente empobrecido para o crescimento intelectual dos alunos. No lugar da discussão, do desafio, da curiosidade, imperam a rotina, a imposição de normas e da autoridade do professor, o desestímulo para o crescimento pessoal. $O$ aspecto predominante na dimensão educação é o disciplinamento, é preciso manter a ordem para o trabalho, para o relacionamento entre pessoas dentro do espaço sala de aula. A lida com o conhecimento explicita as dificuldades do professor para assumir sua função de mediador do conhecimento, evidenciando como isso causa prejuízos aos alunos, pois não os conduz à condição de pessoas com autonomia de pensamento e de ação, capazes de se comprometerem com seu próprio desenvolvimento intelectual e social. Ressalte-se que na pesquisa, abarcamos aulas em públicas e particulares e que não se manifestaram diferenças das aulas nessas diferentes escolas. 


\section{Discussão da pesquisa segundo Theodor Adorno}

As evidências da pesquisa nos permitem discutir o que significa a escola, que sentidos ela revela segundo a posição de Theodor Adorno. Portanto, duas dimensões deveriam emergir das análises das salas de aula como elementos a serem considerados, segundo as posições de Adorno acerca da escola, sua crítica aos processos pedagógicos e sua reivindicação para a escola (Adorno, 1995 a, b, c, d). São eles, a lida com o conhecimento e o processo de formação dos alunos para autonomia.

Adorno não é um pedagogo e não é um representante da Teoria da Educação, portanto não há uma obra sua que vise discutir a educação e as práticas pedagógicas com um intuito de fornecer uma contribuição nesse terreno. No entanto, estudiosos de sua obra apontam que ele revela uma concepção de educação e uma reivindicação para a escola: a educação deve resgatar seu potencial para o desenvolvimento de consciência e de subjetividade; deve se traduzir em autonomia. Para ele, autonomia é um processo do indivíduo que depende de sua experiência educativa e formativa na sociedade, tendo a escola, nesse processo, um papel fundamental (VILELA, 2007; PUCCI, 1995; ZUIN; RAMOS-DE-OLIVEIRA; PUCCI, 2000). Não há dúvidas que podemos considerar como uma das grandes contribuições de Theodor Adorno a análise do processo de dominação cultural que subtrai ao homem sua autonomia de pensamento e ação. Ele não poupa a escola, ao denunciar que ela atua como agencia de dominação, na medida que impõe ao aluno o acesso a informações fragmentadas, que valoriza o resultado de exames de classificação e o mérito no lugar da reflexão e o priva de experiências de autonomia ( Adorno, 1995 a, c). Assim, a escola está comprometida com o processo de reprodução das relações sociais de dominação.

De forma particular, Adorno faz referências à função social da educação formal,aquela pela qual a escola é responsável ao afirmar que o processo educacional consolidado não efetiva a formação de pessoas e, pelo contrário favorece a semifomação. Ele dirige as críticas ao sistema escolar alemão que consolida uma experiência de educação massificada e fortalece o processo de dominação social vigente na sociedade, mas, também, ao mesmo tempo, revela a crença ao valor da formação esclarecida para a edificação da sociedade democrática. O que se tem destacado nessa discussão é a forma reiterada como ele defende uma perspectiva de educação para a autonomia. Fica evidente que Adorno almeja uma sociedade de homens com autonomia de pensamento e de ação, que possam fazer resistência à cultura dominante e então edificar uma cultura verdadeiramente humana, uma cultura a favor do homem - e não uma cultura a favor da dominação.

Mas, nessa discussão, ao lado de como ele reitera a incapacidade da escola em criar os mecanismos de formação - Bildung -, mantendo-se coerente com sua posição fiel aos postulados da Teoria Crítica, ele expressa uma exaltação à escola na 
sua responsabilidade de formação das pessoas, reconhecendo nessa formação a única possibilidade do homem para resistir ao processo de dominação. Para ele, apenas onde a formação represente a independência do pensamento é possível resistir aos ditames da ordem social exterior ao homem, e só com essa condição é possível a edificação de uma sociedade livre e justa, uma sociedade de homens livres que a edifiquem como sociedade onde este homem livre possa viver.

Assim, Adorno parece compreender a educação como um programa deliberado de resistência ao estabelecido, que possa levar as pessoas a compreenderem a contradição imanente na vida social sob o capitalismo e perceberem que é possível ser de outro modo. Nessa condição, a educação edificaria uma possibilidade real de conduzir à Bildung, entendendo esta como um estado de plena autonomia. Todavia, Adorno não quer dizer com isso que tributa à escola a responsabilidade de, sozinha, operar a mudança social. Assumir essa posição seria um equívoco. Se é verdade que se deva creditar a Adorno a defesa que a educação só teria sentido se fosse dirigida para a formação de pessoas dotadas de autonomia de pensar e de agir, não se pode creditar a ele uma proposta pedagógica para desenvolver esse componente, uma vez que, para ele, isso estaria no processo social como um todo e a escola deve ser compreendida na sua relação estrutural dialética negativa com a sociedade. Finalmente, podemos afirmar que seu pensamento sobre educação se assenta em um diálogo com a teoria da educação, o que torna possível esclarecer que implicações a dimensão de educação para a autonomia apresenta para a escola.

Garantir a efetivação da formação integral plena - Bildung - parece ser a reivindicação de Adorno para a escola. A formação é um conceito importante da teoria pedagógica e que tem como significado maior o entendimento de que pela Bildung o sujeito se eleva à condição de sujeito pleno. Entretanto, diferente de uma teoria pedagógica que postula o homem abstrato, o sujeito emancipado de Adorno se eleva à condição de emancipado com plenitude de autonomia nas condições concretas da vida social. E ele se eleva como sujeito pleno através do conhecimento e do uso correto da sua razão, que lhe permite compreender as contradições da sociedade e os mecanismos que tolhem sua capacidade de autonomia. O sentir-se sujeito no mundo, compreendido por Adorno, equivale a ser não-dominado e, para isso, o conhecimento, promovido na e pela escola na relação ensinar e aprender, e a educação, como processo deliberado de elevar o sujeito à condição de vida social com autonomia, são bases para que ele se eleve como indivíduo, que realize a sua formação. Mas, sem autonomia e sem ensino não se processa essa formação. Na história da escola, essas dimensões estão presentes e se relacionam dialeticamente no processo pedagógico, sendo, portanto, dimensões do processo escolar (VON FIEDEBURG, 1992; HEYDORN, 1979). 
Adorno tem em vista esse processo ao insistir que a sociedade deve perseguir sujeitos emancipados e que a escola deve ser dirigida à sua efetivação. Se isso se confirma, podemos concluir que Adorno defende uma boa escola: a que educa, a que ensina e a que incorpora a possibilidade real de formar o homem pleno de autonomia como condição para a vida social.

\section{Conclusão}

Nessa perspectiva assinalada por Adorno, as salas de aula analisadas revelam uma escola que não está apta para preparar pessoas emancipadas. E, consequentemente, devemos terminar defendendo a necessidade de repensarnossas práticas pedagógicas, uma vez que consideramos necessário retomar como princípio que as proposições curriculares para que a escola desenvolva experiências com a lida com o conhecimento e com o desenvolvimento de habilidades sociais pautadas na autonomia, devem ser materializadas na escola - essas são condições para que uma escola caminhe na direção preconizada por Adorno: que a emancipação seja concretizada para os alunos através do pleno acesso ao conhecimento e das condições de desenvolvimento da autonomia.

Consideramos importante assinalar que a metodologia se mostrou um instrumento importante para o desvendamento da escola que não realiza a formação para a autonomia. Fica evidente a necessidade do conhecimento real da escola para que se possa enfrentar o desafio de transformá-la. É fato que a sociedade atual aponta críticas à escola, mas, também, é inegável que cabe a ela um papel importante na formação de pessoas e de uma nova mentalidade que possa levar a sociedade a novas formas de produção e de relações sociais que conduzam à superação das injustiças e dos problemas socioeconômicos e culturais de toda ordem. Mas, para que isso seja possível, a escola real precisa ser elucidada, é preciso formular um conceito sobre a escola no mundo atual, é preciso saber o que ela é. Esperamos que as evidências apontadas e discutidas na pesquisa possam contribuir para um conhecimento significativo dos temas que permeiam a escola, de forma particular aos avanços dos estudos que discorrem sobre a educação escolar, além da teoria curricular e da sala de aula.

\footnotetext{
Abstract

This research has applied an unprecedented methodology in Brazil for classroom studies, the Objective Hermeneutics, created by Ulrich Overmann, at the University of Frankfurt. The methodology has been developed at this University through classroom researches since 2000. Systematic exchanges with this team have enabled training on the method and its experimental application. Instead of observing a lesson and then writing an interpretation of it, the Objective Hermeneutics aims at analytically rebuilding it. The first part of the research consisted of systematic studies of the methodology, its theoretical and methodological structure and operalization. In this paper, we present the empirical research that aimed to
} 
analyze how curriculum proposals are applied in the classroom by posing the following questions: What issues in the current education system are revealed in this process? How do teachers and students experience school today? How do the schools of today reveal themselves in the classroom? This part was developed as a case study in elementary schools and high schools in Belo Horizonte. Theodor Adorno's curriculum theory and education concept support the discussion of the results.

Keywords: Theodor Adorno; Objective Hermeneutics; Curriculum; Classroom.

\section{Referências}

ADORNO, Theodor. Educação após Auschwitz. In: Educação e Emancipação. Paz e Terra: São Paulo, 1995a.

ADORNO, Theodor . Educação para que? In: Educação e Emancipação. Paz e Terra: SãoPaulo, 1995b.

ADORNO, Theodor . Educação contra a barbárie. In: Educação e Emancipação. Paz e Terra: São Paulo, 1995c.

ADORNO, Theodor . Educação e emancipação. In: Educação e Emancipação. Paz e Terra: São Paulo, 1995d.

BRASIL, 1997. Parâmetros Curriculares Nacionais. V.1. Introdução. Brasília: MEC/SEF.

FRIEDEBURG, Ludwig von. Bildungsreform in Deutschland. Geschicht und gesellschaftlicher Wiederspruch. Frankfurt: Suhrkamp, 1992.

GARCIA; Regina L.; MOREIRA, Antonio Flavio B. Currículo na contemporaneidade Incertezas e desafios. São Paulo: Cortez, 2003.

GOODSON, Ivor. As políticas de currículo e de escolarização. Petrópolis: Vozes, 2008.

HEYDORN, Heinz-Joachin. Über den Wiederspruch von Bildung und Herschaft. Bildunsgstheoretische Schrifiten.Band 2. Frankfurt/M: Syndikat, 1979.

MCKERNAN, James. Currículo e imaginação. Porto Alegre: ARTMED, 2009.

MONROE, Paul. História da Educação. São Paulo: Cia Editora Nacional, 1976.

OEVERMANN, Ulrich .Fallrekontruktion und Strukturgeneralisierung. Frankfurt/M. 
1996a. Disponível em: <http/www.rz.uni-frankfurt.de/ hemeneu>. Acesso em: 11 nov. 2009.

PUCCI, B. (Org.). Teoria Crítica e Educação. Vozes: Petrópolis, 1995.

VILELA, Rita Amelia T.; NOACK-NAPOLIS, Juliane. Hermenêutica Objetiva e sua aplicação na pesquisa empírica em educação. Linhas Críticas, Brasília, v. 16, n. 31, p. 305-326, jul. dez. 2010.

VILELA, Rita Amelia T. Teoria Crítica e pesquisa empírica: metodologia hermenêutica objetiva na investigação da escola contemporânea. In: Pucci; Zuin; Lastória. Teoria Crítica e inconformismo: novas perspectivas de pesquisa. São Paulo. Autores Associados.

VILELA, Rita Amelia T.. Críticas e possibilidades da educação e da escola contemporânea: lições de Theodor Adorno para o currículo. Educação em Revista. Belo Horizonte. n. 45, p. 223-248, jun. 2007.

ZUIN, Antonio A.; LASTORIA, Luiz Antonio C.N. (Org.)2010. Teoria Crítica e Inconformismo. novas perspctivas de pesquisa. São Paulo. Autores Associados, 2010.

ZUIN, Antonio Alvaro Soares; RAMOS-DE-OLIVEIRA, Newton; PUCCI, Bruno. Adorno: o poder educativo do pensamento crítico. 2.ed. Petrópolis: Vozes, 2000. 191p. 